NIGEL GLENDINNING

\title{
Influencia de la Literatura inglesa en el siglo VXIII
}

\section{Cosmopolitismo literario del siglo XVIll}

La investigación de influencias internacionales ha sido muchas veces más bien espinosa que provechosa.

Es cierto que hay menos prejuicios acerca del XVIII español ahora de los que había anteriormente, pero no hemos llegado todavía a una situación relativamente serena en la consideración de las fuentes y las imitaciones literarias semejante a la conseguida, por ejemplo, para el siglo XVI, para el cual existen los mismos problemas. Nadie en el día de hoy cree que haya que tachar a Garcilaso por haber imitado a los clásicos o a los italianos. Ningún crítico aseveraría que Cristóbal de Castillejo hacía muy bien en pedir 
que Garcilaso y Boscán ${ }^{2}$ se sometiesen a una especie de inquisición literaria y patriótica.

$Y$, sin embargo, hay todavía quienes creen que la literatura española del siglo XVIII está falta de fuerza poética e interés estético precisamente porque sus autores imitaban a los clásicos y a los extranjeros de vez en cuando.

Me he decidido a hablar del tema, a pesar de sus evidentes escollos, por dos razones. En primer lugar, porque las relaciones literarias y culturales entre España e Inglaterra en el siglo XVIII son todavía mal conocidas, a pesar (le la existencia de alguna tesis doctoral norteamericana ${ }^{2}$ y algunas investigaciones concretas excelentes de menos extensión y más profundidad, como la reciente del profesor Polt acerca de Jovellanos, ${ }^{3}$ y las ya antiguas del profesor Peers que siguen siendo útiles aunque demasiado generales; $;^{4}$ y en segundo lugar, porque hay una tendencia a creer que las relaciones hispanoinglesas no son en realidad sino un aspecto de las relaciones entre Francia y España, dado que se conocían las obras de autores ingleses en España muchas veces a través de traducciones francesas, y 110 directamente. ${ }^{5}$ Mi propósito es aclarar en un princi-

1. Véase su poema "Contra los que dejan los metros castellanos y siintuen Jos italianos”, en B. A. E., tomo 32, Madrid, 1927, pág. 157.

2. Véase Susi Hillburn Effross, English Influence in Eighteenth-Century Spanish Literature, 1700-1808, Columbia University, 1962 (Dissertation Absiracts, XXXIII, 630-31).

3. John R. Polt, "Jovellanos and his English Sources", en Transactions of the American Philosophical Society, nueva serie, Vol. 54, Parte 7, 1964.

4. Veanse "Milton in Spain", en Studies in Phitology, XXIII, 1926, pấgs. $172 \mathrm{y}$ sigs.; "The Inftuence of Young and Gray in Spain", en Modern Latizuage Review, XXI, 1926, págs. 404-18. Después de dada esta conferencia se hil publicado un importante artículo por Alban Forcione titulado "Meléndez. Vuldtes, and the "Esany on Man", en Hispanic Review, XXXIV, 1966. núm. 4 .

5. Véase C. Demerson, Don Juan Meléndez Valdés et son temps, París, 1962, págs: 465 y sgs., y M. Defourneaux, Pablo de Olavide ou l'Afrancesado, Paris, 1959, pág. 67. Reparos semejantes a los míos se encuentran en dos reseñas importantes de libros por Russell P. Sebold en Hispanic Review, XXXIII, 1965, págs. 179.180 y Hispanic Review, XXXIV, 1966, júgs. 354-5. 
pio, en cuanto pueda, la naturaleza y extensión de los contactos entre ingleses y españoles en el XVIII, y luego examinar más datalladamente el interés que hubo en España por algunos autores concretos, poetas todos ellos: Pope, Thomson y Young. Espero aportar algo nuevo acerca de ese interés, sobre todo en algún caso difícil —el de Meléndez Valdés-, y luego ver hasta qué punto es posible sacar conclusiones generales acerca de la importancia y del carácter de ese influjo.

Conste ante todo que la cuestión de influencias en el siglo XVIII no empezó siendo, como desgraciadamente llegó a ser, una cuestión que había que soslayar porque afectaba al sentimiento nacional. No se trataba entonces en la literatura de ir a mendigar a países poderosos las ideas o las obras de las cuales carecían países menos desarrollados. Lo fundamental para los ilustrados en todos los países era aprovechar todo lo que podía ser útil o que era interesante dondequiera que se hallase: reconocer que lo bueno era bueno en España como en otros países. Si Trigueros y Meléndez siguen a Pope, Fielding, Smollett y Sterne sacan fruto de Cervantes, y Defoe del Inca Garcilaso.

Melchor de Macanaz, por lo tanto, no desprecia a los ingleses porque "adaptan a su lengua todo cuanto encuentran bueno y adaptable en las demás lenguas". ${ }^{\circ}$ Lo que se llamaría en el siglo XIX casticismo le parecía un prejuicio al ilustre ministro. Lo mismo parece pensar el padre Feijoo cuando se declara ciudadano libre de la república de las letras. ${ }^{7}$ Y si bien se daba importancia al concepto del clima y a su influencia sobre el carácter de los pueblos en España como en otros países europeos en el siglo XVIII, existían al mismo tiempo muchas

6. Véase Antonio Valladares de Sotomayor, Seminario erudito, Madrid, 1789, Tomo VIII, pág. 136.

7. Teatro crítico universal, II, 10. 
cosas cuya aceptación se quería que fuese verdaderamente supra-nacional, entre ellas la razón y el gusto, bases de la cultura y la erudición. Ignacio de Luzán decía en sus $M e$ morias literarias de París que las causas de la preeminencia de la literatura francesa eran tales que "siempre que en cualquiera otra parte se echen los mismos cimientos, se pongan los mismos medios, y concurran las mismas causas, se conseguirán los mismos progresos y las mismas ventajas". Aún más importante para nuestro caso, ya que se refiere concretamente a la literatura, es la teoría de la elocuencia desarrollada por Antonio de Capmany en una obra publicada en 1777. "Yo creo que la razón y el cora. zón del hombre, así como su interés siempre han sido los mismos", asevera Capmany. "La diversidad de los climas puede alterar o graduar la sensibilidad física, determinar cierto género de vida, y las costumbres que de ella nacen; pero sólo la educación pública o por mejor decir, la forma del gohierno, puede variar, o depravar los sentimientos morales, y hasta la idea de la hermosura real. La elocuen. cia puede variar en las calidades secundarias que siguen el genio de las naciones, y hasta el carácter de los individuos, mas no en sus principios fundamentales, que son del gusto íntimo del hombre, como son: verdad, naturalidad, claridad, precisión, facilidad, decencia"." Distintos autores, según Capmany, tendrían su propio estilo, producto en parte de su país de origen y de su propio temperamento, pero en el fondo la sublimidad de su arte satisface los criterios universales y es igualmente respetable y asequible en todas partes: "Si Rafael pinta la Transfiguración, Miguel Angel representa el Juicio: cada uno pintó su genio,

8. Ignacio de Luzán, ob. cit., Madrid, 1751, pág. 3.

9. Antonio de Capmany, Filosofía de la eloquencia, Madrid, 1777, prólogo, págs. XII.XIII. 
y ambos son grandes y sublimes". ${ }^{10}$ Creo que la misma idea se desprende de otras obras de la misma época de Capmany, entre las cuales no vacilaría en incluir la obra dirigida al Maestro de los eruditos a la violeta publicada por Julián Marías."

Una lectura de Capmany nos hace comprender una verdad de una importancia enorme para nuestro propósito. El neoclasicismo quería ser en la literatura lo que son el cosmopolitismo y el derecho natural en el mundo social del siglo XVIII. La verdadera literatura no es el mero producto de una nación y de un individuo: es universal y debe serlo en todo el sentido de la palabra. Todos los autores de todos los países son iguales ante la ley, o ante las reglas, de la república literaria. La Filosofía de la elocuencia de Capmany es en sí buena prueba de esta verdad. Cita Capmany para ilustrar los distintos tipos de elocuencia trozos de autores bíblicos, clásicos, franceses y muy probablemente italianos e ingleses también, demostrando así la existencia de la belleza en todas partes (nos está haciendo falta un buen estudio de las fuentes de esta obra). Además la misma teoría de la universalidad de la elocuencia se aceptaba en todas partes. No es ni original ni exclusivamente española en Capmany. ¿Cómo iba a serlo? Las ideas fundamentales son las de un inglés, Hutcheson, y se repetirían en la famosísima Retórica de Blair. Capmany podía haberlas leído en el mismo Hutcheson o en Blair, o las hubiera podido conocer también a través de los artículos sobre la belleza

10. Id., ob. cit., págs. XIV-XV. También es interesante lo que Capmany dice acerca del estilo: "Vemos que toda la Europa ha uniformado el suyo, y aunque cada nación tiene su idioma, traje y costumbres locales, los progre. sos de la sociabilidad han hecho comunes las mismas ideas en la esfera de las buenas letras, el mismo gusto, y por consiguiente un mismo modo de ex. presarse" (págs. XVIII-XIX).

11. Véase mi artículo, "A Note on the Authorship of the Comentario sobre el doctor festivo y Maestro de los Eruditos a la violeta, para desengaño de los españoles que leen poco y malo", en el Bulletin of Hispanic Studies, XIII, 1966, págs. 276-83. 
y el gusto de Marmontel y de Voltaire en la Enciclopedia de Diderot, donde se da un resumen de las teorías hutchesonianas. ${ }^{12}$ Pero Capmany las hace suyas, como Garcilaso hacía suyos trozos de Sannazzaro. El concepto de la literatura y las ideas, lo mismo que las ciencias, el comercio y la política mercantil, hicieron que los hombres del siglo XVIII se aproximasen. El gran objeto del saber era, como Cadalso decía, "hacerse los hombres más sociables comunicándose mutuamente las producciones de sus entendimientos, y unirse, digámoslo así, a pesar de los mares y dislancias". ${ }^{13}$ Tomás de Iriarte confesaba que sus mejores amigos eran Horacio, poeta latino, Haydn, músico alemán, y Mengs "el célebre sajón", y aseveraba siempre admitir como amigos a "los hábiles y estudiosos"." "Pintor, músico y poeta", dice, "observan en sus estilos la misma buena elección, - El primor y arreglo mismo". ${ }^{15}$ Otros españoles también reconocían la igualdad de los buenos artistas de todos los países al establecer una imprenta de música en Madrid para publicar obras "entresacadas de las mejores composiciones de Españoles y Extranjeros" en julio de 1770 , anunciándose primero "la obra primera del señor Schwindel", holandés que vivía en Karlsruhe; más adelante obras de Boccherini (italiano que ya estaba en Madrid en 1769), de Cramer (alemán que vivía en Londres) y de Pugnani (otro italiano). ${ }^{16}$

12. Véase sobre todo el artículo sobre la belleza en la Encyclopédie ou dictionnaire raisonné des sciences, des arts et des métiers, ed. consultada, Ginebra, 1778, 3." ed., Tomo IV, págs. 608 y sigs., especialmente págs. 609.613.

13. Véase Los Eruditos a la violeta, Madrid, 1772, pág. 7.

14. Véase la Epístola escrita en 20 de mayo de 1776 a una dama que preguntó al autor qué enemigos tenía, en B. A. E., tomo 63, Madrid, 1871, págs. 35-36.

15. Id., pág. 36 .

16. Véanse la Gaceta de Madrid, 1770, págs. 232, 264; Gaceta de Ma. drid, 1771, págs. 35 (Boccherini), 92 (Rodriguez de Hita), 100 (Brunetti), 204 (Cramer y Pugnani). Para más datos acerca de estos compositores, véase 
$\mathrm{Y}$ aunque con la guerra de la independencia y con $\mathrm{Na}$ poleón comenzó a hundirse de verdad, a mi parecer, el sentido de una cultura cosmopolita y del arte como algo supranacional en España, ${ }^{17}$ incluso por entonces los españoles ilustrados nacidos en el dieciocho difícilmente se deshacían de sus lazos culturales con los demás países, cuya utilidad habían reconocido tantas veces. El mismo Capmany, en su Centinela contra franceses, escrita en 1808 para promover un movimiento en contra de la cultura francesa y una vuelta hacia la española (con jácaras en vez de canciones francesas), sólo rechazó lo especificamente francés (por evidentes razones políticas), pero no la cultura de otros países europeos. ${ }^{18}$

Quizá me haya explayado más de lo debido sobre este punto central del cosmopolitismo literario y artístico del siglo XVIII, que afecta sin duda alguna aún a algunos de los autores españoles que pasan por más castizos, como Ramón de la Cruz, ${ }^{19}$ aunque no a todos. Pero era importante para mí dejar sentado el espíritu con que esos autores ilustrados leían, admiraban y copiaban de vez en cuando obras extranjeras. No se crea que los ejemplos que yo dé más adelante de fuentes inglesas de pasajes de determinados poemas españoles, sean ejemplos que se citan en desdoro de los autores españoles de esa época. Las imitaciones o los ecos de la literatura inglesa en la literatura española

Williams S. Newman, The Sonata in the Classic Era, Chapel Hill, 1963, págs. $241-7,341$ y 722 .

17. EI cosmopolitismo se encuentra, daro está, tan sólo en una minoría, y el cambio se produce ámicamente en aquel grupo. Algún rasgo de espíritu nacional se manifiesta en la defensa de la poesín de Herrera y de Góngora hacia el final del siglo XVIII. Véase mi artículo "La fortuna de Góngora en el siglo XVIII", en Rensista de Fitologia Española, XIV, 1961, [1963], págs. 345-346.

18. Véase Centinela contra franceses, Madrid, 1808, págs. 13-16.

19. La importancia de la influencia de la literatura francesa en Ramón de la Cruz fue notada ya por Cotarelo y Mori en D. Ramón de la Cruz y sus obras, Madrid, 1899, págs. 100, 109, etc. 
de fines del siglo XVIII demuestran el interés que se tenía por determinadas ideas y estilos o géneros determinados, no una falta de inspiración. Es de creer que la mayoría de los autores españoles ilustrados habrán tenido el mismo concepto cosmopolita de la imitación que se encuentra en Trigueros, quien, en el prólogo a la primera de sus poesías filosóficas, dice lo siguiente:

"Yo digo como puedo lo que pienso, y no me desdeño de usar de los pensamientos y expresiones que me acuerdo haber leído en otros, cuando coinciden con mis ideas, y no hallo modo mejor de expresarlas. La expresión mejor es sólo la buena, y la mejor no es más que una para cada pensamiento: ésta es la que busco, y tomo donde la encuentro, ora sea en mi cabeza, ora en la ajena. Nada hay en el mundo nuevo: sólo puede ser nuevo el modo, y conjunto, o sistema. Si éste fuere mío, yo seré su Autor: malo o bueno, según fueren los materiales que he escogido y el orden con que los he vestido y colocado."20

\section{Contactos entre España e Inglaterra y sus circunstancias.}

Hasta ahora he enfocado la cuestión de contactos culturales entre los países europeos en términos generales, $y$ es el momento de considerar las relaciones entre Inglaterra y España de modo más preciso. No cabe duda que esas relaciones fueron afectadas adversamente en determinadas épocas de resultas de la política española que favorecía los contactos con Francia, por haberse firmado

20. Cándido María Trigueros, El poeta filósofo, Sevilla, 1774, Carta del autor al editor, $\mathrm{f} \mathrm{B1} \mathrm{r} / \mathrm{v}$. 
los distintos Pactos de Familia con este país, y tambiẹn como resultado de la guerra con Inglaterra en Portugal en 1762 y el sitio de Gibraltar de 1779-1783.

Tampoco hubo en Inglaterra las ventajas de la creencia religiosa oficialmente ortodoxa y proximidad geográfica, que ofrecía Francia para los que pensaban enviar sus hijos al extranjero a estudiar. Y, sin embargo, el interés por Inglaterra no era tan escaso como se deduciría del capítulo sobre contactos internacionales del gran libro de Sarrailh, a pesar de la buena cosecha de datos que contiene. ${ }^{21}$ Hablemos primero de los españoles que fueron a Inglaterra y que tuvieron conocimientos directos del país y de su cultura.

Abundan sobre todo los contactos de hombres de cien. cia. Una docena de españoles fueron socios de la Royal Society inglesa en el siglo XVIII, ${ }^{22}$ destacándose, en primer lugar, los exploradores y marineros, don Antonio de Ulloa y don Jorge Juan. Después de desempeñar, este último, un papel importante en la expedición científica para medir los grados en la América ecuatorial en 1736 con La Condamine, y otros viajes exploratorios en la costa del mismo continente, Jorge Juan fue muy bien acogido por los científicos ingleses en la década cuarenta, quedán. dose varios meses en Londres en 1748 y $49 . .^{23}$ Fue elegido Fellow de la Real Sociedad en noviembre de 1749, y cimentó sus buenas relaciones con sus colegas ingleses

21. Véase J. Sarrailh, L'Espagne éclairée de la seconde moitié du XVIIe siècle, París, 1954, págs. 337 y sgs.

22. Véase Thomas Thomson, History of the Royal Society from its Institution to the end of the Eighteenth Century, Londres, 1812, apendice IV, págs. XXXIX, XL. XLIV, XLV, XLVI, XIVII, XLIX, LIII, LVI, LXIII, refiriéndose al conde de Montijo, el dr. Cervi, Antonio de Ulloa, el duque de Medina Sidonia, Jorge Juan, Joseph Hortega, Ricardo Wall, Joseph Ignacio Torres, Pedro Dávila, Casimiro Gómez Ortega, el príncipe de Masserano, Joseph Mendoza y Ríos.

23. Véase Sir Archibald Geikie, Annals of the Royal Society Club, Londres, 1917, págs. 32 y 35. 
cenando varias veces con ellos en el Club de la Royal Society. Por aquellos años, estuvo en Londres también don Pedro Maldonado, geógrafo ecuatoriano, que había reunido gran cantidad de noticias de la Historia Natural de América del Sur. Murió Maldonado en la capital inglesa, asistido por su amigo el Dr. Hans Sloane, ${ }^{24}$ ilustre presidente de la Royal Society por entonces, y correspondiente de varios eruditos españoles. ${ }^{25}$ Pocos años después de la muerte de Maldonado, otro científico español que estuvo en Inglaterra fue elegido también Fellow de la Real Sociedad: José Ortega, uno de los muchos estudiosos españoles que viajaban por Europa a instancias del rey, tomando notas de todo lo que pudiera ser útil a su patria, desde el punto de vista científico. ${ }^{26}$ Ortega envió algunos apuntes al gobierno de Madrid, y diez años después su sobrino, Casimiro Gómez Ortega, famoso botánico y literato, estuvo en Inglaterra de orden del rey para estudiar los jardines botánicos de ese país. ${ }^{27}$ Los viajeros ingleses que después le conocieron en Madrid sabían las amistades que tenía con hombres de ciencia ingleses: fue elegido socio de la Royal Society por unanimidad de votos el 4 de junio de 1777, y se correspondía (en francés y en latín) con el famoso explorador y naturalista Sir Joseph Banks, en 1785. Envió muestras botánicas al Jardín Bo-

24. Maldonado estuvo en Madrid en 1744 y fue a París en 1746 antes de trasladarse a Londres al año siguienle. La Condamine se refiere a su muerte en una carta a Voltaire escrita el 25 de octubre de 1759. Hay una copia española de la carta en el Museo Británico, MS. Add. 20,793, ff 300v/303v.

25. Hay varias carlas a Sloane de Juan Salvador, boticario de Barcelona, en el Musco Británico, y algunas de Pedro Maldonado y el Dr. Cervi, médico del rey, entre los manuscritos de Sloane.

26. Véase Thomas Thomson, ob. cit., pág. XLVII. Hay una carta de Ortega fechada el 16 de octuhre de $175^{2}$ en París al ministro José Carvajal y Laneastor, refirićndose a sus viajes por Italia, Francia y Holanda, y remitiondo un papel sobre "el nuéthơlo de hazer los bellos tintés azul y verde que hasta aqua se ha guardido como secreto en Saxonia" (A.H.N., Madrid, Estado, leg. 3.182).

27. Véase mi artículo, "Ortelio en la vida y la obra de Cadalso", en la Revista de literutura, 1958, XIV, núms. 27-28, pág. 16. 
tánico de Oxford y posiblemente porciones de platina a científicos ingleses. ${ }^{28}$ Otros contactos de tipo científico que no carecen de interés son los que estableció en 1788 el marqués de Ureña. A pesar de ser autor del famoso poema La posmodia y creador del regimiento de la Posma, cuyo único objeto era no hacer nada y luego descansar, el marqués era un ilustrado activo. Envió el diario de sus viajes por Francia, Inglaterra y Holanda al conde de Floridablanca. ${ }^{29}$ En Londres, según su diario, visitó a "varios artistas, y entre ellos, el taller del óptico Ramsdem, de cuyos cepillos para aplanar el latón saqué un diseño, como de alguno de sus tornos". Después de visitar al célebre astrónomo Herschel y sus telescopios en compañía del naturalista Sparrman, fue a Oxford a ver la universidad. "Ví aquellos colegios", nos dice, "tomé razón del sistema actual de su universidad, y asistí a una lectura de mineralogía por el doctor Thompson en el Museo de Anatomía. Reconocí las nuevas cárceles, según el plan del viajero Hoghart". Ya se ve que la curiosidad del marqués de Ureña no se limitaba a lo estrictamente científico, y más adelante nos habla de sus viajes por los Midlands y por el norte de Inglaterra, y de sus impresiones del canal del duque de Bridgwater y de la fábrica de porcelana llamada Nueva Etruria, dirigida por Josiah Wedgwood, por entonces recién establecida.

Aún más amplias fueron las impresiones de una estancia en Inglaterra redactadas por Leandro Fernández de Moratín en 1792 y 1793. Las noticias que recoge acerca del teatro se esperaría que fuesen bastante comprensivas, refiriéndose tanto a la historia del teatro en Inglaterra como a su estado en la década noventa. Pero a Leandro

28. Id., loc. cit.

29. Véase A.H.N., Estado, Leg. ${ }^{\circ}$ 4817, Núm. 36. 
Fernández de Moratín le interesaban todos los múltiples aspectos de la vida inglesa: desde las cosas más obvias, como las borracheras del príncipe de Gales, la libertad del culto, y el gran número de suicidios, hasta las menudencias: el número de brindis en las comidas públicas (brindis por el rey, brindis por la confusión de los enemigos de Inglaterra, brindis por la caída de Tom Payne, autor de Los derechos del hombre, etc), los trastos que hacían falta cuando se tomaba el té, y la "enorme magnitud" de los pies de las inglesas. ${ }^{30}$ Tampoco dejaba de tomar apuntes de todo lo que podría ser útil a España: Describe el sistema de socorrer a los pobres en cada parroquia. Saca dibujos de la sierra circular que ve en Southampton, así como de la bomba con dos émbolos para achicar el agua de los navíos, y da una relación bastante extensa del contenido de los gabinetes de historia natural y otros museos interesantes. ${ }^{31}$

Aparte de estas visitas serias a Inglaterra y las de algunos pocos más que fueron allí a estudiar o a aprender un oficio, habría que contar con una buena dosis de estancias harto menos científicas: sobre todo con las de los españoles que pasaban por Inglaterra al correr cortes o que estaban destinados allí como diplomáticos. En la mayoría de los casos no sabemos casi nada de las impresiones de estos viajeros, y sólo podemos afirmar que contribuirían algo a los conocimientos de la vida y cultura inglesas difundidos por España. Entre los embajadores y ministros encontramos algún socio de la Real Sociedad, como el príncipe Masserano, y hombres que estudiaban realmente a fondo la cultura inglesa, tales como Bernardo

30. Véanse Obras póstumas de Leandro Fernández de Moratín, Madrid, 1867, Tomo I, "Apuntaciones sueltas de Inglaterra", págs. 163.165, 171-2, y 177.8 .

31. Id., Tomo I, pégs. 188 y sigs. 
de Iriarte y Bernardo del Campo, más tarde marqués del Campo, proveedor de libros ingleses y amigo de Jovella. nos. ${ }^{32}$ Iriarte dijo que "fue infinito lo que escribió [en Londres]", y se complacía cuando el Consejo le remitía más adelante traducciones del inglés para su censura -como lo hizo, por ejemplo, con las obras de Young, traducidas por Escóiquiz. ${ }^{33}$ Entre los que sencillamente corrían cortes cuando iban a Inglaterra se destaca el conde de Fernán-Núñez, autor de la Vida de Carlos III. Sabemos que tenía amigos ingleses al volver a España, y que se jactaba de haber conocido al capitán Cook, hombre del pueblo de admirables cualidades, que llegó a ser famoso explorador. ${ }^{34}$

Debe añadirse a los contactos científicos y diplomáticos de españoles en Inglaterra otro tipo de contacto igualmente importante: el de los comerciantes. Sabido es que el padre de Cadalso estuvo en relaciones con comerciantes de varios países europeos, entre ellos Inglaterra, y proyectaba una especie de pequeño mercado común. Y Bernardo de Iriarte llevó a Londres en 1761 cartas en inglés de su padre, residente en Tenerife, pidiendo ciertas mercancías a William Burrowes e hijo, y negociando algún asunto de seguros con su colega Richard Madan. ${ }^{35}$

La importancia de conocimientos de inglés para el comercio en aquel momento se desprende muy bien de algún aserto de Campomanes, y de una carta a Ricardo Wall de Simón Antonio de Santander y Rada. ${ }^{36}$ Este pedía

32. J. H. R. Polt, ob. cit., pág. 11.

33. Véase A. H. N., Consejos, Leg. ${ }^{\circ} 51.640$, núm. 36. Bernardo de Iriarte fue encargado de la censura del segundo tomo y remitió su parecer el 3 de febrero de 1797. Su hermano había emitido un veredicto favorable para el primer tomo el 5 de septiembre de 1789.

34. Véase la Carta de Don Carlos de los Ríos, XXII Señor y VI Conde de Fernán-Núnez, a sus hijos, Paris, 1791, págs. 88-89.

35. Véase Museo Británico, MS. Eg. 575 ff 14-15.

36. Véase Museo Británico, MS. Eg. 509 f 64r. Carta del 11 de diciem. bre de 1761 . 
el púesto de cónsul español y agente general de España en Ostende. Aunque era natural de Madrid tenía parientes en Utrecht y había cursado estudios en las universidades de Duay y Lovaina. Conocía bien las lenguas francesa y holandesa, pero lo que le parecía especialmente útil para un cónsul era la adquisición de "bastantes principios de la [lengua inglesa] para traducirla", con que podía aprovecharse "de las luces y noticias contenidas en varios excelentes escritos ingleses sobre ideas de comercio y política".

Estos conocimientos del inglés, lo suficientes por lo menos para leerlo, se encontraban también en algún político importante fuera de la carrera diplomática. Creemos que era el caso del Conde de Campomanes, por ejemplo, a juzgar por su promoción de su estudio en España y por una carta que escribió al historiador Robertson en $1777 .^{37}$

Pero al desarrollo del interés por la cultura inglesa en España, no sólo contribuyeron los viajeros y políticos españoles. $Y$ hay que decir algo de los ingleses e irlandeses que viajaron o vivieron en España en el siglo XVIII, y que ayudarían a su vez a la difusión de ideas anglosajonas en la península.

Tenemos bastantes pruebas de contactos cordiales entre ingleses y españoles desde la década treinta, cuando se estaba preparando en Londres una soberbia edición del Quijote en español. Fue por entonces cuando Lord Carteret escribió por lo menos dos cartas en castellano a Mayans y Síscar, en marzo y abril de 1738, que luego se publicaron, aseverando en una de ellas que sería "siempre muy aficionado a la Lengua i la Gente de España", y que tenía la "buena intención de cultivar la Lengua Española" en Inglaterra. ${ }^{38}$ No sólo estaba muy contento Lord Carteret

37. Hay una copia de la carta a Robertson en el Museo Británico, MS. Add. 17, 633 ff 70-71.

38. Véase Gregorio Mayans y Síscar, Cartas morales, militares, civiles 
del estudio biográfico de Cervantes que Mayans había es. crito el año anterior para la edición inglesa, sino que quería reproducir un retrato de Mayans con la Vida en el primer tomo, pidiéndoselo a través del embajador inglés en 1737, Sir Benjamin Keene. ${ }^{39}$

Gracias a las cartas de éste sabemos los muchos buenos amigos con los que viajeros y diplomáticos ingleses podían contar en la Corte española a mediados del siglo. Y es interesante notar que más adelante varios viajeros ingleses se refieren a las mismas familias que parecen haber permanecido fieles a sus antiguas amistades. Los condes de Montijo, duques de Huéscar, duques de Berwick, más tarde los de Aiba, los duques de Béjar, los marqueses de Tabuérniga, y los condes-duques de Benavente y duques de Osuna, parecen haber tenido especial interés en los contaclos culturales y políticos entre España e Inglaterra. ${ }^{40}$ Son ellos, o sus parientes, quienes acogen muchas veces a los viajeros ingleses en la segunda mitad del siglo y los reciben con frecuencia en sus casas. William Beckford, el autor de Vathek, iba muy a menudo al palacio de Liria a ver a la duquesa de Berwick cuando estuvo en Madrid en 1787, habiéndola conocido anteriormente en París. ${ }^{41}$ El 13 de diciembre, a instancia de la duquesa, se sienta al fortepiano y canta canciones inglesas y arias de óperas francesas. Otros viajeros fueron acogidos con la misma amabilidad y varios afirmaban después que los españoles parecían tener una preferencia por los contactos con in-

y literarias de varios autores españoles, Valencia, 1773, Cartas LXXVII y I.XXIX.

39. Véase Sir Richard Lodge, The Private Correspondence of Sir Ben. jamin Keene, Cambridge, 1933, pág. 9.

40. Véanse Diaries and Correspondence of James Harris, First Earl of Malmesbury, Londres. 1844, Tomo I, págs. 54 y 129; y Sir Richard Lodge, ob. cit., págs. 11,135 y 489.

41. ' The Journal of William Beckford in Poreugal and Spain 1787-1788, Londres, 1954, págs. 287-288. 
gleses y que, en realidad, a pesar de las apariencias polí ticas, odiaban a los franceses. James Harris, que estuvo en Madrid entre 1768 y 1771, decía que, una vez que el viajero inglés había logrado convencer a los españoles que no era ni judío ni bárbaro, se le acariciaba más que en Francia. "Sienten los españoles una antipatía tremenda para con los franceses", aseguraba Harris, "a quienes llaman 'gavachos'. Los alemanes y los ingleses les resultan más simpáticos, y a los portugueses y los italianos tienen casi la misma antipatía que a los franceses". ${ }^{22}$ Es muy posible que estos juicios fuesen efectos del narcisismo o inocencia de Lord Malmsbury. Pero sabidas son las cordiales relaciones que Harris tenía con el conde FernánNúñez y tenemos referencias también de su amistad con el conde de Montijo; Harris notaba que los duques de Béjar y San Esteban y don Agustín de Lancastre imbuían al futuro Carlos IV con sus propios prejuicios en favor de Inglaterra. ${ }^{43} \mathrm{Y}$ no deja de ser sugestivo el que otros viajeros no diplomáticos hayan tenido la misma impresión a principios de la década setenta. ${ }^{44}$

No debemos despreciar del todo las observaciones de diplomáticos y viajeros ingleses, a pesar de las circunstancias políticas y personales en las cuales se emitían. En los casos en que unos buenos conocimientos del español pueden demostrarse - en los de Harris, de Sir Benjamin Keene y Lord Carteret, por ejemplo--, podrían tener algún valor.

Ayudaría a los contactos cordiales de viajeros la exis-

42. Diaries and Correspondence of James Harris, Londres, 1844, I, pág. 49.

43. Id. I., pág. 54. Véase también A. Morel-Fatio, Études sur l'Espagne, París, 1888, Tomo III, pág. 105.

44. Véase, por ejemplo, Richard Twiss, Travels through Portugal and Spain in 1772 and 1773, Londres, 1775, pág. 167 (Condesa-Duquessa de Bena. vente), y pág. 142 (el odio que sienten los españoles para con los franceses). 
tencia en el siglo XVIII de un creciente número de libros. útiles para quienes querían estudiar los idiomas, de los cuales los viajeros podían disponer. En las bibliotecas españolas de la época encontramos ejemplares de los Verdaderos principios de la lengua inglesa en francés, por V. J. Peyton (Londres, 1756) o la Gramática inglesa y castellana de Stefani, publicada en Valencia en 1784. Y en Inglaterra se manejaban con frecuencia los diálogos de Sobrino, o la nueva gramática española de Giral del Pino ("Teacher of the Spanish Language", o sea, profesor de español en Inglaterra), que se editó en Londres en 1766 con otras dos ediciones antes del fin del siglo, una de ellas hecha más bien para españoles. En 1752, según la correspondencia oficial del ministro español en Londres, D. Félix de Abreu, tanto Lord Granville como el famoso Lord Chesterfield (el de las Cartas a su hijo) esperaban con ansias la llegada del Diccionario de la Real Academia. ${ }^{45}$

No exageremos la importancia de tales libros, que no parecen en el día de hoy más que curiosidades en la historia de la enseñanza del español en Inglaterra. Lo único cierto es que con tales ayudas o sin ellas bastantes viajeros ingleses lograron aprender mucho no sólo de la vida española sino de su cultura. La existencia de tales libros demuestra la existencia de un mercado. Si la relación publicada por alguno de los viajeros, como Swinburne, por ejemplo, pudo dar lugar a un comentario muy poco favorable por parte de José Nicolás de Azara, los escritos de otros fueron muy útiles para los ingleses que querían saber algo bueno de España y no sencillamente críticas adversas, y fueron estimados de los españoles. Para las letras españolas, nada más útil para un inglés que las Cartas de un viajero inglés

45. Archivo de Simancas, Estado, Leg. ${ }^{\circ} 6920$ antiguo. Carta de Félix de Abreu fechada en Londres el 22 de junio de 1752. 
en España en 1778, sobre el origen y progreso de la poesía en aquel país de Sir John Dillon (Londres, 1781); ${ }^{46} \mathrm{y}$ para las bellas artes, no era de menos provecho el libro de Richard Cumberland. ${ }^{47}$

El autor del libro de viajes más interesante para espanoles e ingleses, sin embargo, fue Alexander Jardine. Amigo de Jovellanos, aunque éste no parece haberse fiado siempre de su opinión algo revolucionaria en asuntos de política, es uno de los ingleses que es cierto ejerció alguna influencia sobre sus amigos y conocidos españoles. No sólo viajó por España, sino que allí residió varios años como cónsul en La Coruña. A través de su libro vemos cómo trató de convencer al hijo del conde de Peñaflorida para que fuera a estudiar a Inglaterra, donde, según Jardine, varios paisanos suyos estudiaban por entonces química, filosofía natural y experimental $u$ oficios mecánicos. ${ }^{48}$ También vemos cómo le gustaba hablar de Inglaterra con los españoles que habían estado allí. Le interesaba notar la representación de alguna obra dramática traducida del inglés. ${ }^{49}$ Igualmente sabemos que prestó libros ingleses a sus amigos. Es lástima que no sepamos más de las posibles actividades semejantes de otros ingleses e irlandeses que estuvieron varios años en España, como el célebre Bowles,

46. Letters from an English Traveller in Spain en 1778 on the Origins and Progress of Poetry in that Kingdom, Londres, 1781. Algo sobre literatura española hay también en Rev. Edward Clarke, Letters concerning the Spanish Nation, Londres, 1763; Joseph Baretti, Tolondron, Londres, 1786, y Robert Southey, Letters written during a short Residence in Spain and Porlugal... with some account of Spanish and Portuguese Poetry, Brig. tol, 1797 .

47. Richard Cumberland, An accurate and descriptive Catalogue of the several Paintings in the King of Spain's Palace at Madrid; with some account of the Pictures in the Buen Retiro, Londres, 1787. Antes de la publicación de este libro los ingleses hubieran podido tener alguna idea del desarrollo de la pintura en España y de los cuadros y esculturas que se encontraban en España, gracias a las ediciones inglesas de libros de Palomino: en español, Londres, 1742 y de nuevo en 1744; en inglés, Londres, 1739.

48. Véase An English Officer, Letters from Barbary, France, Spain, Portugal, Londres, 1788, II, pág. 24.

49. Ob. cit., pág. 164 . 
por ejemplo, que vivió en Madrid y en Bilbao y escribió un libro sobre la historia natural de España y fue bien acogido en la Corte ${ }^{50}$ o como O'Briant que construía barcos en la península, o como Price y Kelly que tenían fábricas en Asturias, ${ }^{51}$ o como Smallwood, Balf, Greatex y Cadwell, que establecieron fábricas de tela en la península hacia 1788, empleando en algún caso los métodos de Arkwright. ${ }^{52}$

Y sería interesante saber hasta qué punto pudieron influir en las letras aquellos irlandeses de origen, como Ricardo Wall y Bernardo Ward, que tanto influyeron en la política y en la economía española a mediados del siglo, sobre todo en el desarrollo de teorías mercantilistas, teniendo muy en cuenta la afirmación de Wall de que no pensaba hubiese nacido en España "nadie más español que yo lo soy". ${ }^{53}$

\section{El estudio del inglés y de libros ingleses en España.}

El amontonar datos de nombres y de contactos relativamente pequeños y aislados sólo nos permite vislumbrar las posibilidades de influencia inglesa en España que ya no cabe duda existían en la segunda mitad del siglo XVIII. Para que aquella influencia viniese a ser importante en la

50. Véanse An English Officer, ob. cit., II, págs. $37-38$ (Bowles) y 222; también el prefacio del libro de William Bowles, Tratado sobre el ganado merino, traducción inglesa, Londres, 1811.

51. Véanse An English Officer, ob. cit., II, pág. 43 (Obriant) y J. R. Polt, ob. cit., págs. 10-11.

52. Véase Museo Británico, MS. Eg. 513, ff. 90-95.

53. Véase su carta a José de Carvajal fechada en Londres el 30 de noviembre de 1752 en Simancas, Estado, Leg ${ }^{\circ} 6920$. 
literatura y llegase a cuajar, haría falta probar dos cosas: la existencia de autores españoles con buenos conocimientos del inglés y la existencia de libros ingleses asequibles para ellos. Y esto es más difícil. El hecho en cuanto al idioma es que el inglés se estudiaba muy poco en España en comparación con el francés. ${ }^{54}$ Vamos a considerar los pocos datos que tenemos. En Barcelona en el Seminario de Cordelles entre 1755 y 1757 sabemos que Casimiro Gómez Ortega pudo estudiar el inglés. ${ }^{55}$ Es probable, por lo tanto, que en otros colegios se pudiera aprender el idioma. Pero a decir verdad, éste es el único caso que yo he podido documentar antes de la década ochenta. Tengo la idea de que en los colegios de jesuitas españoles, alguna vez se estudiaba también por aquellos años. Pero pruebas fijas no tengo. Dos jesuitas españoles puede que tuviesen conocimientos del inglés, ya que apreciaban la literatura inglesa: el famoso padre Andrés, y el padre Arteaga. Y sé que algún jesuita más quería aprender el idioma en la

54. Sabido é que el francés se estudiabà en el Real Seminario de Nobles en Madrid desde muy temprano. Es interesante notar lo que se dice sebrca de su estudio on unos Ejercicios literarios.+ que ofrecen al público los cavalleros seminaristas i discipulas de las escuelas pias de esta ciudad de Vatenta, Valencia, 1773, pág, 18: "Como la lengua francesa se ha hecho de un uso cuasi indispensable en nuestros tiempos, se ha procurado variar los egercicios del Colegio con una hora de estudio todos los días de la misma lengua. Por to cual, todos los de tercera i cuarta classe leerán en este idioma, i traducirán al Castellano en ctaluquier libro que no fuere facultativo. I algunos que están más egercilados volverán del Custellano al Francés, i compondrán cartas a aquellos asuntos que son más frecuentes en la vida eivil." Se empezaron cluses de inglés en el Seminario de Nobles de Madrid en 1780. Mariano Surges decía entonces que "nada hay en este uño de nuevo (en ol Seminario) sino la traduceín de algo de Griego, Ingles y Francís" (Simancas, Gracia y Justicia, 696 antigno) $Y$ siete años despućs se dio lieencia a Bartolomé Neshix para establecer academia en Mavlrit a fin de enseñar ol inglés. En muchas escuelas más, en cambio, * podfa aprender el frantés. (Véase Archivo Histárico Nacional Sala de Alcaldes de Casa y Conte. Catálogo por materias, Madrid, 1925, págs. 3 y 264).

55. Véase la Relación de los mérilos, servicios y exercicios literarios del Dr. D. Casimiro Gómez Ortega, primer catedrático jubilado del Real Jardín, Madrid 1809 (MSS. del Real Jardín Botánico, Madrid, 5." División, Núm. 5, f. 325 r/v). 
déćada sesenta, ya que Cadalso dio clases de inglés en el Seminario de Nobles de Madrid en 1760 al padre Diego Lozano, escribiéndole varias cartas en el mismo idioma para que no olvidara sus lecciones. ${ }^{56}$ Pero otros españoles que sabían inglés parecen haberlo aprendido o perfeccionado en sus viajes, como el mismo Cadalso o Bernardo de Iriarte, por ejemplo, o lo habían estudiado sólo a través de gramáticas, diccionarios y con la ayuda de comerciantes, no llegando a escribir ni hablar corrientemente, como parece haber sido el caso de Jovellanos en Sevilla y Meléndez en Segovia. En realidad, da mucho que pensar acerca del estudio de los idiomas en España en la década sesenta, el hecho de que Vicente García de la Huerta haya sido enviado a Francia antes que a otros países "a perfeccionarse en los idiomas europeos menos comunes en ésta." ${ }^{.57}$ Irónicamente, las guerras con Inglaterra y sobre todo el sitio de Gibraltar, parecen haber dado nuevos impulsos al estudio del inglés en España. Algunos oficiales del ejército pudieron lucir sus conocimientos en aquella situación: Cadalso, en el intercambio de prisioneros en Gibraltar, y algún oficial menos conocido, pero también interesante, como don Manuel Aguirre (que publicó una serie de artículos imbuidos de ideas de la ilustración europea en el Correo de Madrid). en Menorca. ${ }^{58}$ Después del sitio, sabemos que el conde de Noroña "se aprovechó de [la] calma para perfeccionarse en las lenguas inglesa,

56. Véase mi artículo "Cartas inéditas de Cadalso en castellano, latín, francés e inglés a un padre jesuita", en el Boletín de la Biblioteca Menéndez y Pelayo, XLII, 1966, págs. 97.116. En una de las cartas declara que el inglés no estaba à la mode en 1760 , art. cit., pág. 104 .

57. Véase Museo Británico, MS. Eg. f. 75.

58. Véase la carta de Ricardos a Miguel de Múzquiz fechada el 9 de julio de 1782 (Simancas, Guerra Moderna, Leg" 1.187): "es un oficial de muchas esperanzas por su aplicación, conocimientos matemáticos y posesión de Lenguas, en especialidad la Ynglesa, por cuio motivo... fue empleado con utilidad en Menorca." 
francesa e italiana",59 antes de lanzarse a la carrera diplomática en San Petersburgo. A pesar de estas pruebas de interés y conocimientos, no parece que el estudio del inglés fuera muy difundido ni siquiera a fines del siglo. Gracias a Jovellanos, se enseñó el inglés en el Real Instituto Asturiano, pero otros que sabían el inglés no creyeron que su difusión fuera tan útil e importante. Manuel de Aguirre, por ejemplo, a pesar de su interés por el idioma y sus conocimientos del pensamiento de la ilustración inglesa, sólo recomienda un puesto de maestro francés al elaborar su proyecto para el establecimiento de un seminario patriótico Aragonés para la Real Sociedad Aragonesa en 1785 - proyecto interesantísimo, por otra parte, en el que propone el estudio de las teorías de Condillac y el Ensayo sobre el mérito y la virtud de Diderot. ${ }^{60}$

Esta falta de instrucción en el idioma hacía que muchos aspectos de la cultura inglesa fueran más o menos ignorados en España. Las investigaciones científicas sí se conocían. Bastantes libros médicos y científicos ingleses fueron traducidos al español a partir de la década setenta, y extractos y reseñas de ellos fueron publicados en el Correo literario de la Europa. Y la revolución francesa sólo dificultó momentáneamente la introducción de libros científicos, que nunca sufrieron mucho por razón de la censura, como sufrieron otros tipos de libros. A pesar de lo que se ha dicho acerca de la imposibilidad de la enseñanza de Newton en las universidades españolas, no faltaban ejemplares de sus libros en las bibliotecas particulares y en las de algunos colegios; ${ }^{61}$ y el artillero que iba

59. Justo Pastor Fuster. Biblioteca Valenciana, Valencia, 1830, II, páginas 381.382 .

60. Manuel de Aguirre, Sistema de Sociedades Patrióticas y de Seminarios o casas públicas de educación, Madrid, 1785, pág. 107 (véanse también las págs. 94-95).

61. En la biblioteca del Real Seminario de Nobles en Madrid, despué de la expulsión de los jesuitas, había varios libros de Newton en latín y 
a la Escuela de Artillería de Segovia a estudiar en 1764, sería "émulo de Newton" y con Locke penetraría "el caos del entendimiento", según el parecer, algo irónico, del marqués de Valdeflores. ${ }^{62}$ Pero las huellas de la literatura inglesa, en cambio, son más difíciles de encontrar: en primer lugar, porque la mayoría de los autores eran protestantes (Pope es una excepción), cuyas obras no podían correr con la misma facilidad en España en el siglo XVIII que las de autores católicos, y en segundo lugar, porque no había tanta gente que pudiese entender obras en inglés, como ya hemos visto. ${ }^{63}$

Lo que nos está haciendo mucha falta, a decir verdad, es un estudio de todos los catálogos de bibliotecas españolas del XVIII que se puedan encontrar. La aportación del profesor Jorge Demerson, en su magnífico libro sobre Meléndez Valdés, y los importantísimos datos sobre la biblioteca del poeta que nos dio, son muy útiles. También lo son las listas de libros de Olavide publicadas anteriormente por Marcelin Defourneaux. Y, sin embargo, nada se puede deducir de lo publicado hasta ahora acerca del contenido de la biblioteca típica (si en rigor la hay) del ilustrado español. He tenido la curiosidad de examinar dos catálogos hechos probablemente a principios del siglo XIX, de bibliotecas de ilustrados españoles, para ver hasta qué punto pueden compararse con las de Meléndez Valdés y Olavide. Una de ellas, la de La Serna Santander, demuestra la

en francés (véase A. H. N. Universidades, $\operatorname{Leg}^{\circ}$ 688), En la biblioteca de La Serna Santander había un ejemplar de las Transacciones filosóficas en inglés (véase Museo Británico, MS. Eg. 604).

62. Véase la "Carta del marqués de Valdeflores al P. Antonio Eximeno sobre la oración que éste pronunció en la abertura de la Escuela de Artillería de Segovia" (Museo Británico, MS. Eg. 553, pág. 75). El marqués ironiza acerca de la falta de buenos matemáticos en España.

63. A pesar de ello se recogieron bastantes noticias de la literatura inglesa, traduciéndose algunos poemas, en El espíritu de los mejores diarios (véanse los Núms. 5, 30, 72, 125, 127, 138, 140, 147, 170, 177 y 252, por ejemplo). 
mișma afición a los libros franceses que las de Meléndez y Olavide (Voltaire, Rousseau, Montesquieu, incluso Molière, etcétera). ${ }^{64}$ Pero la otra, la de los duques de Osuna (quizá la que tenían en uno de sus palacios tan sólo), no tiene un solo libro en francés, a pesar de tener en total casi cinco mil tomos $;^{65}$ se trata, por lo tanto, de una biblioteca catorce veces más grande que la de Meléndez Valdés, pero diecisiete veces menos grande que la del ministro Llaguno. ${ }^{66}$ En la biblioteca de Osuna es cierto que hay algunos libros extranjeros, pero todos son traducciones. Además, éstas son, por la mayor parte, libros de devoción (Bossuet, Croiset y Bourdaloue), libros científicos (Duhamel, Vézillet) y libros sobre educación (Rollin). Pero lo que me interesa verdaderamente en esta conferencia es la sección inglesa de tales bibliotecas. A juzgar por las cuatro bibliotecas mencionadas, los libros ingleses escaseaban en las colecciones de ilustrados españoles. Libros en inglés, poquísimos: doce en la biblioteca de Meléndez, uno (de Newton) en la de La Serna, ninguno en las de Osuna y Olavide. Traducciones francesas de libros ingleses o de autores ingleses no faltan, sin embargo: veinticuatro en la de Meléndez y veinticuatro en la de Olavide, once en la de La Serna Santander, y cuatro en la de Osuna. ${ }^{67}$ Deduciríamos de un poema de Tomás de Iriarte, que la situación en la biblioteca de su tío Juan de Iriarte no había sido muy distinta en cuanto a libros ingleses:

64. Museo Británico, MS. Eg. 604, "Lista de los libros de Don Fernando de la Serna Santander".

65. Museo Británico, MS. Add. 17.464, "Catalogue of the Duke of Ossuna's Library".

66. El MS. del Catálogo de los libros de Llaguno fue vendido por J. L. Gili de la Dolphin Book Company, Oxford.

67. El mismo hecho ha sido notado por Russell P. Sebold en sus reseñas de libros de Defourneaux y Demerson. Véase la nota 5 arriba. 
Junta las ediciones más correctas

De griegos y latinos oradores,

Y las obras selectas

De poetas también e historiadores;

Apreciables escritos castellanos,

Muchos de los que Francia ha producido,

Con algunos ingleses e italianos... ${ }^{68}$

Los hermanos Iriarte habrán añadido algún que otro libro inglés, sin duda, pero es de notar que hay una lista de libros extranjeros entre los papeles de don Bernardo de Iriarte en la cual se encuentran, una vez más en traducciones francesas, obras de Milton, de Thomson, de Young, de Ossian, más un tomo de varios poemas en francés imitando el inglés. ${ }^{69}$

\section{Influencia de la poesía inglesa. Algunos casos concretos.}

Quisiera ahora examinar más detenidamente la influencia en España de algunos de estos poetas que Iriarte tenía o quería tener, para ver hasta qué punto es posible hablar de una influencia inglesa significativa en la poesía española. Me interesa, antes de empezar, disentir de una opinión emitida por mi buen amigo, el profesor Demerson, en su libro sobre Meléndez Valdés. Para él los cambios de texto y de atmósfera introducidos por los traductores franceses de algunos poetas ingleses, eran tan notables que no era posible hablar propiamente de influencia inglesa en

68. Tomás de Iriarte, Colección de obras en verso y prosa, Madrid, 1805, II, pág. 69.

69. Véase Museo Británico, MS. Eg. 602, ff. 250-252. 
muchos casos -sobre todo en el de Young. ${ }^{70}$ Yo creo que hay bastantes lugares en que no hay cambio alguno de sentido en esas traducciones, y en muchos casos, creo que es imposible distinguir entre una posible influencia directa y otra indirecta. Es cierto que pudieran existir influencias indirectas en algunos casos. Pero creo que hay bastantes casos en los que la influencia de la literatura inglesa a través de traducciones no fue tan indirecta como se ha aseverado, a pesar de ser las versiones en prosa y no en verso. Más adelante volveremos sobre ello.

Empecemos por considerar el caso de Pope. Tres poetas españoles se inspiraron en sus obras en la década setenta de modo palpable, es decir, bastante antes de la primera traducción española (1790), y todos ellos conocieron el inglés: José Cadalso, Tomás de Iriarte y Cándido María de Trigueros. Las huellas de Pope en Cadalso no son muy profundas, pero no dejan de ser interesantes. Se encuentran, sobre todo, en Los eruditos a la violeta, obra en la que se refiere concretamente al poeta inglés y a sus dos ensayos, sobre el hombre y sobre la crítica. Era natural que la composición de Los eruditos llevase a Cadalso a pensar en los libros de crítica, mayormente en obras como la de Pope, donde se mezclaban las gracias y las observaciones serias. Y me parece evidente eco de Pope la referencia al efecto de la música de Timoteo en la Lección de Domingo ("¿Qué músico moderno italiano, o alemán, hará hacer al Gran Visir de los turcos los excesos que Timoteo hizo a Alejandro, a quien dominaba tanto con la música, que le hacía pasar del odio a la ternura, de la ternura al rencor, del rencor a la piedad, y así por todas las demás pasiones humanas?")." Al leer estas palabras, ¿cómo

70. G. Demerson, Don Juan Meléndez Valdés et son temps, París, 1962, págs. 468-470.

71. Los eruditos a la violeta, Madrid, 1772, pág. 62 . 
no pensar en las de Pope en su Ensayo sobre la crítica, donde cuenta la anécdota, recordando el famoso poema de Dryden El festín de Alejandro, en el que se encontraba también? ${ }^{72}$ También las actitudes frente a la literatura patria y la extranjera, la moderna y la antigua, en Los eruditos, parecen tomadas del mismo poema de Pope. Tras leer a Cadalso: "Despreciad todo lo antiguo, o todo lo moderno: Escoged uno de estos dictámenes, y seguidlo sistemáticamente", y luego, "con igual discernimiento escogeréis entre nuestra literatura y extranjera." ${ }^{\text {73 }} \mathrm{Y}$ después de notar los rayos, truenos, centellas y granizo, que los partidarios de una parte arrojan sobre los de otros partidos, ¿cómo no pensar en el siguiente pasaje de Pope?:

Some foreign writers, some our own despise;

The Ancients only, or the Moderns prize.

Thus Wit, like Faith, by each man is apply'd

To one small sect, and all are damn'd beside.

Meanly they seek the blessing to confine,

And force that sun but on a part to shine,

Which not alone the southern wit sublimes,

But ripens spirits in cold northern climes. ${ }^{74}$

$\mathrm{Al}$ adaptar, como a mi ver lo hace Cadalso, este gracioso pasaje, evita la referencia chistosa a las creencias religiosas que no hubiera podido publicar en España. Tam. bién añade elementos que cambian el estilo epigramático del original, aunque no el sentido, haciéndolo más retórico, a la manera de las obras jocoserias españolas, cuya tradición Cadalso seguía en esta obra. Los eruditos a la violeta no deja de ser una obra española por dos o tres de sus cuatro costados, por lo menos. $\mathrm{Y}$ en otros escritos de Cadalso hallamos el mismo prurito por adaptar chistes

72. Véase Essay on criticism, I, vv. 375-383.

73. Los eruditos a la violeta, ed. cit., págs. 66-67.

74. Essay on Criticism. I, vv. 394-401. 
tomados del inglés para el público español, empleando ejemplos sacados de la literatura o la vida española. En una carta a Tomás de Iriarte, se mofa de las rimas inevitables que se encuentran en unos debilísimos poemas sobre la muerte del padre Sarmiento. Y el pasaje recuerda un lugar muy parecido en que Pope ridiculiza la falta de invención en las rimas (Ensayo sobre la crítica, vv. 350354). ${ }^{75}$ Sin embargo, al dar un ejemplo concreto recurre Cadalso a La Perinola de Quevedo, y los versos "Bajaba por lo duro del peñasco / una hormiga vestida de damasco." 76 Huelga decir que el correspondiente de Cadalso, Tomás de Iriarte, conocía tanto el Ensayo sobre la crítica de Pope como La perinola de Quevedo.

El profesor Sebold ha encontrado ya bastantes recuerdos del Ensayo sobwe la crítica de Pope en Tomás de Iriarte, y sabido es que hay, por lo menos, una cita de un pasaje de aquel poema en inglés en Los literatos en cuaresma." Pero es muy posible que Iriarte recordara también El Ensayo sobre el hombre al redactar su poema fragmentario, El egoísmo. Aunque el desarrollo del poema de Iriarte le lleva a una nota pesimista acerca de la natu. raleza del hombre y de la naturaleza de determinadas socie-

75. Además de estos ejemplos de imitación, podrín parangonarse las aseveraciones de Pope acerca de la mezcla de virtudes y vicios (Essay on Man, II, vv. 205-210) en el mundo, con las afirmationes de Cadalso sobre el mismo tema en las Cartas marruecas (Cartas XXI y XLIII). La doatrina acenca de la virtud que debe seguir el hombre de bien en la misma ohra de Cadalso (Carta XVII: "la viutud sola es la cosa que es más amable euanto tás la conocemos y cultivamos") es muy parecida is lo que dice Pope en su Ensayo sobre et hombre (IV. vv. 309.325). El tema de los nobles innitiles surge tanto en Pope (Essay on Man, IV, 193-308) como en Cadalso; y la crítica del noncepto de la fana se encuentra también en los

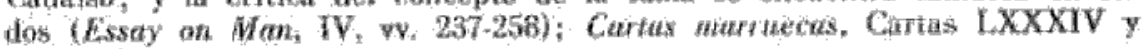
LXXXV).

76. Véase Nigel Glendinning, Vida y obra de Cadalso, Madrid, 1962, pág. 182, nota 27 .

77. Ob. cit., por D. Amador de Vera y Santa-Clara, Madrid, s. a., pág. 6. Véase también Russell P. Sebold, Tomás de Iriarte: Poeta de "Rapto racional", Cuadernos de la Cátedra Feijóo, Oviedo, Núm. 11. 
dades que falta en el poema de Pope, la teoría central de que el interés egoísta es el móvil, tanto de las virtudes como de los vicios, es la misma que la del Ensayo sobre el hombre. Incluso el estilo epigramático recuerda a veces a Pope, como los versos siguientes, por ejemplo:

Sólo en los hombres dura

La idea de su bien, firme y segura:

Se afanan por el bien, el bien esperan,

Y hasta el mal, por lograr el bien, toleran. ${ }^{78}$

Sin embargo, El Ensayo sobre el hombre, inspiró de modo mucho más palpable a Trigueros, cuyo caso, por lo tanto, es mucho más interesante. Está bastante claro que empezaba sus poesías filosóficas pensando en el autor inglés, al que se refiere en la Carta del Autor al Editor, invocándole en los primeros versos del primer poema: $E l$ Hombre:

Dime, sublime Pope, Tú, reflexivo Genio, Que unes con Arte tanto el Juicio, y el Ingenio:

Britano Horacio, dime, Tú que con tal cuidado, Tú, que con tal acierto el Hombre has estudiado:

Dime, Pope, las señas deste soberbio hombre,

Cuéntame en qué se funda la vanidad del Hombre.

Ahora bien, las referencias concretas a autores de este tipo, muchas veces no significan nada. Pero el hecho es que buena parte de esa primera poesía filosófica se basa en el Ensayo sobre el hombre de Pope, y más que nada, en la epístola segunda de aquel poema. El propósito de conocerse a sí mismo, aunque es tanto el de Pope como el de Trigueros, no debe detenernos: tiene antecedentes en Pascal, Cicerón, Platón y muchos más; pero el largo pasaje en que el poeta sevillano da ejemplos de la inconsecuencia del hombre, pudo muy bien haberse inspirado en el pasaje

78. Véase B. A. E., Tomo 63, Madrid, 1871, pág. 41. 
de la primera epístola, en el que Pope habla del variado empleo del buey, que ahora ara, ora es víctima del hombre y ora es una deidad egipcia. ${ }^{79}$ De modo más obvio, el trozo en que Trigueros alude a las distintas posibilidades del hombre y los diferentes conceptos que tiene de sí mismo en distintos momentos, parece partir evidentemente de dos pasajes de Pope:

What would this Man? Now upward will he soar And little less than Angel, would be more;

Now looking downwards, just as griev'd appears

To want the strength of bulls, the fur of bears...

$$
[\mathrm{I}, 173-6]
$$

Tanto la estructura de este pasaje como su sentido, nos recuerda a Trigueros:

Ya nuestro altivo Ingenio admira su excelencia, Ser un nuevo Dios cree, y tener su potencia:

Ya abatido su orgullo vé sus necesidades,

$\mathrm{Y}$ envidia de un insecto dos mil comodidades. ${ }^{80}$

Pope repite la misma idea en términos más escuetos en la segunda epístola (verso 8), donde describe la posición del hombre en estos términos: "In doubt to deem himself a God, or Beast" (dudando si debe considerarse un dios, o una bestia). Pero otro lugar encontramos más adelante en Trigueros, donde se hace eco, de una manera incluso más clara de Pope, al hablar de la soberbia humana, consecuencia de sus conocimientos científicos. Es de notar que Trigueros invoca de nuevo a Pope antes de empezar el pasaje que nos interesa:

Lánzate, Inglés sublime, lánzate en esta mente,

Préstame la vemencia de tu Musa eloqüente. ${ }^{81}$

79. Essay on Man, I, vv. 61.68.

80. El poeta filósofo, Sevilla, 1774, f. Cl. r.

81. Id., f. $\mathrm{D} 2$ v. 
Reza así el pasaje:

Id, sobervios Mortales, medid envanecidos

De la ancha Creación, los rumbos no medidos,

Reglad a vuestro grado el fluxo de los Mares,

Convinad bien de soles esos altos millares,

Fixad el peso al aire, mandad a los Planetas,

Prescivid ( sic) los caminos de los tardos Cometas,

Calculadnos del tiempo la oscuridad ligera,

Y del Astro del Día, governad la carrera,

Subid aun más arriba: id con Platón al cielo,

De la verdad sagrada rasgad el Santo velo

Vé, Mortal; quanto has hecho a tu altivez es poco,

Ya fuiste temerario, sublímate, y sé loco. ${ }^{82}$

Esta vez se trata más bien de una traducción de Pope que de una adaptación. Todo esto se encuentra en Pope y en el mismo orden se encuentran los mismos detalles. Incluso la referencia a Platón, como más adelante una referencia a Newton están allí en términos semejantes. ${ }^{83} \mathrm{Y}$ hay una crítica de los nobles inútiles lo mismo en Trigueros que en Pope. ${ }^{84}$ Recuérdese que en la versificación igualmente Trigueros parece haber imitado en un principio el ritmo de cuatro acentos principales, que se encuentra en Pope. Sólo después de empezada la publicación de la serie de poemas le dijeron que había acertado a descubrir la forma métrica de los antiguos poemas españoles como los de Berceo.

A pesar de las semejanzas con Pope que hemos notado en Trigueros, la mayor parte de la serie de poesías filosóficas se aparta de las ideas del inglés, aunque volvemos a encontrar ecos de sus ideas en la décima poesía, La Reflexión, donde la idea de la gran cadena de los seres (idea,

82. Id., ff. D2 v / D3 r.

83. El poeta filósofo, Sevilla, 1774, f. D3 v. Compáranse Essay on Man, II, vv. $31-34$.

84. Compárense los versos en que Trigueros critica a los nobles "que no sirven de nada" con Essay on Man, IV, vv. 193 y sigg. 
por otra parte, muy vulgar en el siglo XVIII) recuerda indefectiblemente a Pope. No nos sorprende, por lo tanto, que algún contemporáneo español de Trigueros le haya llamado "el Pope español.",85

Estos poemas filosóficos de Trigueros disfrutaron de cierto éxito en la década setenta. Según el autor gustaron a extranjeros, notablemente a ingleses y a alemanes, y no sólo a españoles. A través de las cartas de Meléndez Valdés vemos cómo el joven poeta los leía y los comentaba en su correspondencia con Jovellanos, criticando más que nada la manera difusa de Trigueros en La Reflexión, flaco que ya le hemos encontrado al examinar alguno de los puntos de contacto entre él y Pope. ${ }^{86}$ También critica de soslayo algún pasaje que parece apoyar la teoría de las ideas innatas rechazadas por Locke en su Ensayo sobre el entendimiento humano, y compara el modo de desarrollar sentencias filosóficas con el de otros autores de aquel tipo de obra, con Montesquieu (El Templo de Gnido) y con Young.

En realidad, otros poemas de Trigueros hubieran podido sugerirle a Meléndez aquella última comparación con Young, sobre todo el segundo de los poemas filosóficos, $L a$ Desesperación (1777), en el que se examina entre otras cosas la cuestión del suicidio, analizada también anteriormente por Young en sus Noches.

El creciente interés por la poesía filosófica en España en las décadas setenta y ochenta conduciría tanto al estudio de las Noches de Young como al de los poemas de Pope

85. De una anacreóntica inédita de desconocido autor ("Lo que mis pocos años"), sacamos lo siguiente: "La docta Poesía / on musical conciets / ha hecho servir Iriarte / a mis sabios proyectos, / y con fábulas dulces / reprelicande severo / intrusos insolentes / en mi retrete honesto. / También le soy deudora / al Bético Triguexos / que es por su ingenio, y arte $/$ el Poppe de estos liempos" (Museo Británico, MS. Eg. 553, f. 141 v.)

86. Véase la Carta II a Jovellanos escrita en Salamanca el 24 de agosto de 1776, en B. A. E., Madrid 1871, pág. 75. 
y de Milton. $A$ Young se le leería en inglés o en las tra. ducciones francesas o italianas de aquella obra. La versión francesa de Le Tourneur, fue publicada varias veces a fines de la década sesenta y principios de la setenta y tuvo gran fortuna en Europa. El primer autor español en cuyas obras encontramos ecos evidentes de Young es, como se sabe, Cadalso, que hubiera podido leer con igual facilidad el original inglés o la versión francesa. ${ }^{87}$

Ya en mi edición de las Noches lúgubres procuré subrayar los casos en que Cadalso se estaba acordando a mi ver de "los pensamientos y el estilo" de la obra de Young. ${ }^{88}$ Me referí concretamente a seis lugares en que las ideas de Cadalso parecían tener una relación con las de Young. Hubiera podido añadir dos pasajes más: el de los pájaros que cantan con la venida del alba al final de la primera noche de Young como en la de Cadalso; y la confrontación entre el poeta y su adversa fortuna a principios de la tercera noche lo mismo en Young que en Cadalso. Pero éstas son pequeñeces y las semejanzas principales son: 1) la idea de una obra filosófica en que se medita sobre la muerte y la vida después de la pérdida de una persona querida; y 2) el estilo retórico con muchas repeticiones, exclamaciones y suspensiones, y otros recursos de ese tipo. Debiera haber notado un punto de contacto más: la importancia de la amistad y la fraternidad de los hombres frente a la desgracia, que es uno de los tópicos principales de las Noches lúgubres, y es también tema central de la primera noche de Young. "¿Qué soy yo", dice Young, "cuando me

87. Las cartas que Cadalso escribió en inglés a uno de sus maestros jesuitas, el padre Diego Lozano, demuestran plenamente su dominio del jesuítas, soma. publicarán estas cartas inéditas de Cadalso próximamente en el Boletin de la Biblioteca Menéndez y Pelayo.

88. José de Cadalso, Noches lúgubres, edición, próloga y notas de Nigel Glendinning, Clásicos Castellanos, Madrid, 1961, págo. xIviii-1t, 3, 12. 14, 17 y 27. 
compadezco de mí mismo tán sólo? En la edad madura y en la infancia nuestra única esperanza es la ayuda de los demás. Enseñarnos a ser amables y benévolos es la primera y última lección de la Naturaleza. El corazón egoísta merece todo el dolor que siente: El dolor generoso exalta al hombre y disminuye el dolor" ${ }^{89}$ Pero, mientras que Cadalso está de acuerdo con Young en todo esto, en lo demás de la obra está muy lejos de él. En las Noches lúgubres, Cadalso no sigue al poeta inglés en sus vuelos religiosos y su optimismo. Al fin y al cabo el autor español parece quedarse con lo humano rechazando lo divino: la crítica racional de la superstición; la aceptación de la muerte, de la injusticia y las adversidades; la ayuda del prójimo que sufre también. Es curioso notar cómo Cadalso aprovecha de una manera parecida sus principales fuentes españolas, sirviéndose de la parte del Libro de la Oración de Fray Luis de Granada en la que se está meditando sobre la fragilidad humana y la vida efímera del hombre, y de la parte de un romance que trata de la muerte inesperada de una de dos jóvenes que se quieren. De estas dos obras también Cadalso rechazó los momentos de triunfo y de esperanza: la meditación sobre la resurrección de Fray Luis y la milagrosa vuelta a la vida de la amada en el romance. ${ }^{90}$

Para una influencia más profunda y más amplia de Young en la literatura española de la segunda mitad del siglo XVIII tenemos que examinar otro poeta más optimis-

89. La amistad no es tan sólo un tópico importante en la primera Noche de Young. En la última noche vuelve a surgir, y la armonía de los planetas representa emblemáticamente la amistad.

90. Otra meditación sobre la muerte del siglo XVIII que Cadalso hubiera podido conocer, también se difiere de las Noches lúgubres por tener un capítulo sobre la resurrección. Se trata de la Pintura de la muerte, del marqués Caraccioli escrita en la década sesenta. La traducción española de Nipho fue publicada en 1783 y de nuevo en 1785,1787 y 1789; el original francés en 1761 y de nuevo en 1767. 
ta, y más religioso a mi ver: Meléndez Valdés. Ya varias veces se ha hablado de la influencia de Young en algunos poemas de Meléndez: en La noche y la soledad (poema en que cita a Young), ${ }^{91}$ y, a través de Le Tourneur, en la Oda a la muerte de su hermano, cuyo plan preliminar en prosa contiene varios pasajes en francés de Le Tourneur como ya ha demostrado Demerson. ${ }^{92} \mathrm{Y}$, sin embargo, hay algunas odas más, a mi ver, donde la influencia de Young salta a la vista de manera igualmente obvia. Me interesa examinar en primer lugar la Oda Vanidad de las quejas del hombre contra su hacedor. Ya en los versos 12 y siguientes, cuando Meléndez se refiere a la idea egocéntrica del universo que tiene el hombre orgulloso (" ¿La luna plateada para él solo / No recibe la luz que al suelo envía?") se nota un eco de la Primera Noche de Young al parecer (la pregunta 'Hangs out the sun his lustre but for me, / The single man?': ¿Es para mí tan sólo para quien el sol ofrece su brillo?) aunque hay un pasaje muy parecido en el Ensayo sobre el hombre, de Pope, que Young sin duda tenía en cuenta y que Meléndez también hubiera podido conocer. ${ }^{93}$ Aún más llamativo, sin embargo, es el parecido entre Meléndez y Young en un pasaje posterior del mismo poema en que Meléndez se refiere al lugar del hombre en la gran cadena de los seres. Reza así:

La modesta razón no encumbra el vuelo

Sino hacia sí se vuelve, y asombrada

Ve la inmensa cadena

Que ata el abismo al cielo.

$¿$ Del infinito en medio y de la nada

Que es el hombre ignorante?

91. Véase William E. Colford, Juan Meléndez Valdés, New York, 1942, págs. 188-190.

92. G. Demerson, ob. cit., pág. 468.

93. Essay on Man, I, vv. 131-140. 
Young en la primera noche se refiere igualmente al hombre como "eslabón distinguido en la cadena sin fin de los seres, de la deidad en medio y de la nada". de notar que la palabra 'inmensa' aparece en la traducción de Le Tourneur). ${ }^{95}$ Más adelante Meléndez dice que el amor "es la grande ley que vivifica todo ... ama a tu hermano", lo cual, como ya hemos visto al hablar de Cadalso es uno de los temas de las Nockes de Young, y tema también, no lo olvidemos, de la tercera epístola del Ensayo sobre el hombre, de Pope. ${ }^{96}$

En otras odas de Meléndez también hallamos pensamientos que nos recuerdan las Noches de Young: la idea de que tan sólo un dios podría comprender a Dios, por ejemplo, que encontramos en la Oda VI Al ser incomprensible de Dios, está (con casi los mismos términos) en la novena Noche de Young. ${ }^{97}$ En otros casos es más difícil desentrañar una mezcla de influencias de Young y de Cadalso, tratándose del ambiente de la Noche: la Canción de un infeliz que sin haber dormido toda una noche, se

94. Young, Night Thoughts, I, vv. 74-75.

95. Les Nuits d'Young. Marseille, 1770, pág. 12. ("Anneau brillant, il occupe le milieu dans la chaîne immense des êtres qui descend depuis Dieu jusqu'au néant.")

96. Después de dar esta conferencia se ha publicado un importante artículo sobre la influencia de Pope en este poema que encuentro bastante convincente en sus líneas generales. Se trata del artículo de Alban Forcione, "Meléndez Valdés and the "Essay on Man", Hispanic Review, XXXIV 1966, Núm- 4. Sin embargo, me parece que la influencia de Young en algunos lugares es igualmente probable, aunque el sistema de preguntas y respuestas y el movimiento del poema son más cercanos a los del Ensayo de Pope que a las Noches de Young. Peers también encontró huellas de Young en esta oda (véase Modern Language Review, XXI, 1926, pág. 411).

97. "The more of wonderful $/$ is heard in Him, the more we should ansert / Could we conceive llim, God he could not be; / Or He not God, of we could not be men. I A God alone call comprehend a God!" Compárese este pasaj̃e con el siguiente de Meléndez Valdés (Poesias, Va. lladolid 1797, III, pág. 4): "Ella / mi razón / se pierde en el excelso abismo / De tu lumbre esplendente; / Y te adora, señor, por esto mismo / Mas ciega y reverente. / Pues si le fucra comprehenderte dado, / Igual a ti seria: / El cetro te quitara; y mal tu grado / Tu trono ocuparía." 
queja del vecino día, es buen ejemplo de ello; también la Elegía a la muerte del hermano de Meléndez, cuyos planes en prosa contienen evidentes ecos de las Noches lúgubres de Cadalso. ${ }^{98}$ Pero lo que distingue el caso de Meléndez del de Cadalso en cuanto a su interés por Young es el relativo optimismo de aquél. El punto de vista de Meléndez se parece mucho más al de Young que al de Cadalso. De algún otro poeta español de la misma generación se puede decir lo mismo, aunque sigue vigente en él también la influencia de Cadalso. Nos referimos al conde de Noroña, otro autor que hubiera podido leer a Young en inglés, ya que traduce a Dryden y a otros poetas ingleses, y no sólo a través de traducciones francesas. Su soneto Retrato de la tristeza del Doctor Young que se publicó primero en el Correo de Madrid es sobradamente conocido. ${ }^{99}$ Más significativos, en cambio, me parecen otros poemas de Noroña: la Elegía La noche triste, el poema Tristeza en la ausencia y, sobre todo, el poema filosófico La muerte, en donde se encuentran muchos de los temas que surgen en las Noches de Young (la noche misma, la igualdad de los hombres ante la muerte, las artes que no perduran, la inutilidad de las riquezas, y la crítica del suicidio). Estos ejemplos y poemas nos ayudan a comprender hasta qué punto había lectores de Young en España antes de la publicación de la traducción española de Escói-

98. Lat vampana en Meléndez "que me recuerda aquel (son) que despedazó mi corazón, en la más triste noche... no yo la tendrá más infeliz y llena de horrores en todo el curso de mi Irabajosa vida" puode ser recuerdo parcinl del principio de la Noche primera de Cadalso. Eco nás obvio hay en ol pasaje que se encuentra al final del segundo Plan, donde Meléndez se refiere a los relámpagos y a los horrores de los elementos lo mismo que Cadalso en el comienzo de las Nockes lúgubres.

99. Véase F. Allison Peers, "The Influence of Young and Gray in Spain", en la Moderi Language Review, XXI, 1926, pág. 409. El sonoto fue publicado con la letrilla A la muerte de Don Joseph Cadahalso imitándole", "Ves los pesares que un tiro", en cl Correa de Madrid, núm. 289 , del 29 de agosto de 1789 , Tomo V, pág. 2.328. 
quiz. ${ }^{100}$ No olvidemos la carta que Leandro Fernández de Moratín escribió a Ceán Bermúdez desde Montpellier el 20 de marzo de 1787 en la cual se alude a "aquellas tristísimas Noches, que ni usted ni yo queremos leer, por la razón de haberlas leído".01 Tres años más tarde en el Correo de Madrid se publicó un poema anónimo en que se expresa una más honda y menos equívoca admiración por el poeta inglés y sus pensamientos en los siguientes términos:

y con Young silenciosos nos entremos

en blanda pa\% por estas soledades,

do en sus sublimes Noches meditemos

mil divinas verdades

y a su voz lamentable enternecidos

repitamos sus lúgubres gemidos. ${ }^{102}$

Creo que el éxito de Young, más duradero en España que el de Pope a mi ver, es consecuencia de dos factores:

Primero, el contenido filosófico y religioso de las $\mathrm{No}$. ches, muy interesante en una época en que los poemas filosóficos al estilo dieciochesco empezaban a escribirse en España.

Segundo, el hecho de que muchos de los pensamientos que se expresan en el poema podrían relacionarse fácilmente con la poesía española de los siglos XVI y XVII. El lector español ilustrado habrá disfrutado sin duda de los temas de la ilustración y las observaciones acerca del sui-

100. El primer tomo de Obras setectas de Eduardo Young, espurgadas de todo error, traducidas del inglés al castellano, por Juan de Escóiquiz, fue sometido a Tomás de Iriarte para su consara el 23 de julio de 1789 (véase A, H, N, Consejo, Leg ${ }^{0} 51.640$, núm, 36).

101. Obras póstumas de D, Leandro F'ernández de Moratin, I, Madrid, 1876, pág. 76. Moratín se imagina a un joven pretencioso traduciendo una Noche de Young en el prólogo: a su Mojigata (ob. cit., I, påg. 157).

102. Al final del poema se dice "se cree ser su autor B. M. V." El epígrafe es Hominum commercia vilans, y el poema empieza "Ven, dulce soledad, y al alma mía". (Véase Correo de Madrid, Tomo VII, Madrid 1790. págs. 159-160.) 
cidio, del comercio, del lujo y del ocio que se encuentran en Young; pero habrá notado sin duda pasajes que le traerían a la mente trozos de Fray Luis de León o de Quevedo. ${ }^{103}$ No sorprende, por lo tanto, el que Meléndez haya escrito poemas, cuyas ideas se derivan de Young o Pope, en estrofas inspiradas en Fray Luis. En cuanto al elemento sepulcral que tanto gustó a los románticos no creo que haya sido tan importante en la época que examinamos. La obra de Young es una obra francamente antiromántica, no lo olvidemos. Siempre que emplea Young la palabra "romántico" se trata de algo que hay que evitar o rechazar. ${ }^{104}$

No diría yo tanto del último poeta inglés que quisiera mencionar: James Thomson. Al emplear la palabra "romántico" este poeta, dejó ver su gusto por lo exótico y lo pintoresco. ${ }^{105} \mathrm{Su}$ poesía gustó en parte por ello, a causa del creciente interés por lo pintoresco en España. Pero creo también que su poema Las estaciones gustó en parte por razones parecidas a las que explican el éxito de Young: por las ideas filosóficas y sociales que expresa. Una vez más se nos pinta, en Las Estaciones de Thomson, un universo bien organizado, una gran cadena de los seres de la cual los hombres forman parte - la gran cadena que en

103. Pasajes como el siguiente de la Noche $\mathrm{V}$ recuerdan indefectiblomente a Quevedo: "Each moment on the former shruts the grave. / While man is growing life is in decruse, / And tradles rock us nearer to the tomb. / Our birth is nothing but our death begun, / As tapers waste that instant they take fire". El concepto que Young tiene del mundo como lugar de sombras y prisión no dejaría de recordar al lector español la Noche serena, de Fray Luis de León, como lo haria también la contemplación del cielo estrellado en la Noche IX de Young.

104. La palabra "romántico" significa más bien lo irracional y fatuo en Young, y todo su poema es un elogio de la razón humana y el orden divino establecido en las cosas. "So far from aught romantic what I sing" ("lejos de todo lo que sea romántico mi canción"), dice Young en la Noche VIII. En la Noche VII, habla de "locuras románticas".

105. Hay "una montaña romántica", "una vista" y "unas formas románticas" y "un deseo romántico" en Thomson (véanse sus Poetical Works, ed. consultada, Edimburgo 1883, págs, 60, 91, 116 y 137). Lia versión española traduce "romántic" por "pintoresco" en estos lugares. 
Inglaterra iba pasando de Pope a Young y a Thomson y de Pope a Rousseau y otros en Francia también. Esta cadena impone sus deberes: en Pope el ejercicio de la razón que corrige las malas tendencias del egoísmo; en Young, la creencia en Dios; y en Thomson, el deber social. En Thomson encontramos no sólo un elogio de la vida del campo sino reflexiones económicas y humanitarias acerca de aquella vida. Muy fácilmente podremos comprender cómo sus poesías hayan llegado a gustar a quienes querían algo más útil que la sencilla tradición anacreóntica y el menosprecio de corte, y podían apreciar un nuevo tipo de poesía pastoril en que se trataba de la vida vigorosa del campo (lejos del lujo afeminado y malsano de las ciudades) en términos que bastaban para apoyar las teorías fisiocráticas.

Thomson es un poeta al que se cita mucho en España en la segunda mitad del siglo. Nipho es uno de los primeros que alude a él; ${ }^{106}$ Trigueros le incluye en una lista de poetas que se debían leer como dechados de la poesía filosófica. ${ }^{107}$ En algunas bibliotecas españolas había ejemplares de la traducción francesa, en alguna otra -la de Meléndez por ejemplo- había también el original inglés. Y poca diferencia hay entre el original y la traducción. El prólogo del traductor francés en la edición que Meléndez tenía (Londres, 1779) dice lo siguiente: "Mi objeto ha sido dar a mi nación a Thomson tal como es... El mérito de la traducción está para mí en su fidelidad exacta" ${ }^{108}$ Claro está que las imitaciones francesas de

106. Véase su Estafota de Londres, Madrid, 1762, Introducción de estas cartas, pág. xxil. ("Na me faltarán a la mano, para fundar con más solidez mis pensamientos, las sutilezas de Thomson, las gracias festivas de Akenside...").

107. Véase la carta a Jovellanos del 13 de septiembre de 1778 (G. Demerson, ob. cit., pág. 563).

108. Ob. cit." Avertissement ("Mon dessein a été de donner à ma Nation Thompson tel qu'il est... Quant au mérite de la traduction que 
Thomson - Saint-Lambert, Dorat, ' etcétera - muchas veces dificultan la cuestión de influencias en los poemas españoles que describen las estaciones del año. Es difícil saber si los españoles recordaban el original, una traducción francesa o una imitación francesa. A pesar de ello quisiéramos sacar a luz algún caso inédito del influjo de Thomson en España donde la cuestión es, a mi ver, clarísima. Se trata de un poema de Meléndez Valdés muy conocido: Los segadores. El profesor Demerson ha encontrado cierta semejanza entre este romance y el Estío del imitador francés de Thomson, Saint-Lambert. ${ }^{109}$ Pero se podría demostrar mayor parecido entre el poema de Meléndez y el Otoño de Thomson. En el pasaje cuyo parecido con Thomson me parece del todo evidente, Meléndez pide a los segadores que dejen algunas espigas para los pobres. Dice así:

Todos a su providencia [la de Dios]

Cual menesterosos claman,

$\mathrm{Y}$ en manos paternales

Piedad y alimento hallan.

Hállelo el pobre en las vuestras:

Si de ellas tal vez se escapa

Quebrada la rica espiga,

Guardaros bien de apañarla.

Con negligencia oficiosa

Dejadla, amigos, dejadla

A arbitrio de la indigencia,

Que sigue vuestras pisadas.

En ella su pan del día

De vuestra bondad aguarda

je fais consister tout entier dans une exacte fidélitê, c'est à ceux nous a cul sa langue est familière, que je m'en rapporte"). Pueden compararse estos asertos con los de Le Tourneur en el prefacio de su versión de las Noches de Young: "au reste, j'ai tâché de traduire aussi littéralement que j'ai pu, à raison de mon talent, et de la differénce du génie des deux langues".

109. Véase G. Demerson, ob. cit., pág 477. 
La inocencia desvalida,

O la ancianidad cansada. ${ }^{110}$

He aquí el pasaje muy semejante que se encuentra en la versión española del Otoño de Thomson que se publicó en Madrid en 1801:

El rastrillo al rastrillo le sucede

Recogiendo los débiles despojos.

¡O labradores! evitad en ello

Un cuidado prolixo u ambicioso:

Dexad, dexad con liberal descuido

Alguna que otra espiga en el rastrojo,

Pues de la misma caridad es el hurto

Que cometen los ánimos heróycos.

Ofreced un tributo tan sencillo

En agradecimiento generoso

Al Dios de la cosecha que derrama

En vuestros campos bienes abundosos;

Al par que tristes tantos desvalidos

Arrastrados del hambre, sin socorro,

En tropas llegan cual los paxaritos

Que por los aires baxan presurosos

A recoger con su piquillo hambrientos

Los granos esparcidos..."11

Algunos otros lugares del mismo poema nos recuerdan la misma sección de Las estaciones de Thomson, ${ }^{112}$ y otros poemas de Meléndez tienen, como es sabido, ecos de

110. Es el romance XVI de la edición de 1820 -véanse las Poesías de Melêndez Valdés, edición, prólogo y notas de Pedro Salinas, Clásicos Castellanos, Madrid, 1925, págs. 206-207. No sabemos ottándo fue compuesto este romance por el poeta. Es pastible que fuese después de la publicación de la versión española de Las estaciones. Es curíso notur cómo Meléndez remata el pasaje ditado excepcionalmente con cuatro versos asonantados:

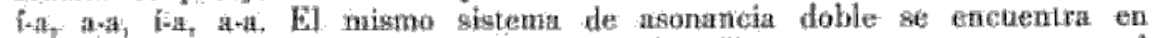
esta sección de la tradueción espafiola de Thomson, andive no en el original inglés, con versos asunantados en i-o además def ovo básico.

111. Véanse Las estaciones del año, poema de Jayme Thompson (sic), traducido por D. Benito Gómez Romero, Otoño e Invierno, Madrid 1801, pág. 14.

112. Compárense los versos de Meléndez —“Así al buen Dios imitamos / que nos da con mano franca"- con los de Thompson -"Think, 
Thomson, notablemente la Oda primera ("El invierno es el tiempo de la meditación"). ${ }^{113}$

Espero haber dicho lo suficiente ya para recordarles la importancia indiscutible de la influencia de Pope, Young y Thomson en algunos poetas y poemas españoles. El género de influencia varía según el autor que está imitando, pero en general los pensamientos y las ideas son lo que preferentemente se imitan, y con menos frecuencia la manera concreta en que los pensamientos se expresan. Esta in. fluencia de las ideas es sin duda difícil de rastrear, y como ya ha notado el profesor Demerson hay poemas españoles cuyas fuentes son muy numerosas. ${ }^{14}$ Algunos de los poemas que he mencionado tienen sin duda fuentes españolas o francesas (incluso bíblicas o clásicas) de la misma importancia que las fuentes inglesas de las cuales he hablado. Pero a pesar de ello creo que la influencia inglesa en la poesía española del dieciocho no está completamente desprovista de interés. He insistido sobre la poesía más que otra cosa, porque no creo que otros aspectos de la cultura inglesa hayan tenido el mismo influjo. Había referencias a algunas novelas inglesas en España en el XVIII - las de Richardson sobre todo- y algunos españoles las leían, entre ellos Olavide (en francés) y Jovellanos y posiblemente Trigueros en inglée ${ }^{115} \mathrm{El}$ teatro inglés no influyó

oh, grateful think! / How wood the God of Harvest is to you, / who pours abundance o'er your flowing fields".

113. Ya sugirió la semejanza entre este poema de Meléndez y el Invierno de Thomson, William E. Colford, en su libro Juan Meléndez Vaddếs, Nueva Yatk, 1942, págs. 195.6. Sin fijarnos en detalles, es cierto que la misma serie de pensamientos que hallamos en Thomson surge abreviada en Meléndez: la búsqueda de tranquilidad, el rechazo de las vanidades de la vida, la venida de la muerte bajo la forma del invierno, pero la esperanza de renovación gracias al orden y armonía del universo. Lo que se omite es toda la parte bistórica y política de Thomson. También se añade algo de Luis de León: el fínal del poema, sobre todo, recuerda el final de La noche serena.

114. Véase G. Demerson, ob. cit., pág. 475.

115. Véase la biblioteca francesa de Olavide, segundo apéndice en el importante libro de Marcelin Defourneaux, Pablo de Olavide ou l'Afran. 
casi nada en comparación con el teatro italiano $-\mathrm{y}$ no se puede comparar aquella influencia más que lejísimamente con la del teatro francés. Tan sólo en la filosofía y en las ciencias influyó tanto Inglaterra en España en aquella época, como ha demostrado el profesor Polt en el caso de Jovellanos. Y a mi ver el influjo de la poesía inglesa era muchas veces una continuación de la influencia de la filosofía inglesa. Trigueros se quejaba de los poetas salmantinos en 1778 por no tener "otro Apolo que el Amor, ni otra materia que sus delicias, ni otro estilo que el dulce". ${ }^{116}$ Era lástima, según él, que no pensasen "en lo grande, en lo sublime, en lo útil", y menciona como poetas que había que seguir a "Homero, Virgilio, Pope, Milton, Thomson, Voltaire y Klopstok". ${ }^{117}$ En un siglo filosófico era lógico escribir poesía filosófica, y de ese tipo de poemas los poetas ingleses podían ofrecer buenos ejem. plos universalmente admirados.

Una cosa más quisiera decir antes de terminar. Después de echar una ojeada a la materia que hemos examinado hoy, urge saber si es posible sacar alguna conclusión concreta acerca de los momentos y los círculos en los que la influencia inglesa en España más se hacía sentir. Está claro que una simpatía para con Inglaterra existía en muchas partes entre hombre de negocios, intelectuales y aristócratas, aunque para el pueblo el iajero inglés como el viajero italiano, francés y alemán, seguía siendo objeto de burlas, a juzgar por las tonadillas escénicas. Pero creo que es posible ver la verdadera importancia de la influencia inglesa en dos o tres tertulias y dos o tres momentos.

cesado; también J. H. R. Polt, Jovellanos and his Enghish Sontres, pág: 10. Es posible que Trigueros haya leído aquellas novelas en inglés, a juzgar por lo que dice en Mis pasatiempos, Madrid 1804, I, págs. XV-xvs.

116. Véase su carta a Jovellanos en G. Demerson, ab, cit., pág. 563.

117. Id., loc. cit. 
Yo diría que sin la tertulia de la Fonda de San Sebastián y sin el círculo de Olavide en Sevilla, más o menos coetáneos, la influencia inglesa en la literatura española por lo menos no hubiera llegado a ser ni siquiera lo que fue. En Sevilla el mismo Olavide, Jovellanos, Trigueros y probablemente Capmany y otros personajes menos conocidos como Donato Arenzana y Vázquez Ortega, ${ }^{118}$ hablarían bastante de la literatura inglesa. Recuérdese que fue durante su estancia en Sevilla cuando Jovellanos aprendió el inglés y cobró interés por la cultura inglesa. En Madrid, es inconcebible que tres anglófilos como Cadalso, Gómez Ortega y Tomás de Iriarte no hablasen de la literatura inglesa, y es posible que una parte de su afición pasase al joven Leandro de Moratín que tantas veces les escuchaba hablar en casa de su padre Nicolás. De estos hombres y a través de sus cartas y otros escritos, iría muy posiblemente difundiéndose el interés por la cultura inglesa en otros círculos: Cadalso, al hablar de sus $\mathrm{No}$ ches lúgubres en Salamanca se habrá referido a su modelo Young, que Meléndez y sus amigos llegaron a conocer bastante bien. Desde Sevilla llevó Jovellanos su nueva afición a Madrid y a Gijón. Y la cultura inglesa llegó a difundirse aún más al final del siglo (quizá por ser algo menos republicana que la francesa) gracias al interés de Jovellanos, y luego merced a las traducciones españolas de Young, Hervey, Thomson, etcétera, que salieron a fines de la década noventa o en los primeros años del siglo XIX, y al interés por la literatura inglesa de algún periódico. ${ }^{119}$ Casos aislados

118. Donato de Arenzana fue uno de los poetas sevillanos que escribieron sobre el tema miltoniano de La caida de Luzbel, Sevilla 1786. La carta de Antonio Vázquez Ortega a Don Casimiro Olalla sobre el poema que se publicó entre los papeles preliminares de la caida, contiene numerosas referencias a autores ingleses $y$ a sus eseritos.

119. Notable ejemplo es el Espiritu de los mejores diarios literarios que se publican en Europa, Madrid 1787-1789, de Cristóbal Cladera. Entre las numerosas citas de la literatura inglesa hay alusiones al Vathek de 
de influencias se dan (Noroña, Nifo, el marqués de Ureña) pero en uno de aquellos casos por lo menos, el de Noroña, la amistad con Cadalso habría contribuído algo a su interés.

Ahora bien ni la tertulia de la Fonda de San Sebastián ni el círculo de Olavide fueron sencillamente anglófilos. Mucha más importancia tenía la cultura francesa para ellos, y se interesaban igualmente por aspectos de la cultura italiana por no hablar de la española, preferida de todos. He aquí cómo volvemos inevitablemente a nuestro punto de partida. Lo fundamental para los autores españoles que hemos examinado, eran las ideas, tanto en la literatura extranjera como en la patria, y algunas veces la manera de expresarlas. Y en todas partes había ideas en el siglo XVIII. Los españoles, como los autores de otros países, recogían todo lo que les parecía bueno y rechazaban lo que era malo según su parecer. Tomaban mucho de Francia, algo de Inglaterra y de Italia, algo también de Alemania al final del siglo. Muchísimo más tomaban de la literatura española y de la latina. Si Cadalso toma algo de Young en sus Noches lúgubres y un poco de Hervey, toma también algo de los romances tradicionales de la difunta pleiteada, bastante de Fray Luis de Granada, y un poco de Vicente Espinel, de Quevedo, de Séneca y de Horacio. Muy bien podemos no siempre estar de acuerdo con las ideas de lo bueno y lo malo en la literatura que tenían aquellos hombres del dieciocho, pero por lo menos reconozcamos su inteligencia y sinceridad. Son los hombres quienes tienen ideas y estilos y caracteres, no los países: los sujetos, no los objetos. $\mathrm{Ni}$ siquiera eran todos aquellos autores tan dogmáticos en sus ideas acerca del estilo como algunas veces nos parecen. Recuérdese aquel pasaje, a mi ver

Beckford (el 7 de julio de 1787), a Ossian y sus imitadores (el 12 de julio de 1787 y el 21 de julio de 1788), a Milton (el 2 de marzo de 1789), y a Beattie y ous ideas sobre lo sublime (Núms. 207-211). 
admirable, de las Cartas marruecas de Cadalso en que está contrastado en términos generales el estilo de los españoles con el de los árabes. Confiesa que es imposible juzgar cuál es el mejor:

"¿Cuál tiene razón? No lo sé. No me atrevo a decirlo, ni creo que pueda hacerlo sino uno que ni sea africano ni europeo. La naturaleza es la única que pueda ser juez; pero su voz ¿dónde suena? Tampoco lo sé. Es demasiada la confusión de otras voces para que se oiga la de la común madre en muchos asuntos de los que se presentan en el trato diario de los hombres".

No cabe duda que en este pasaje Cadalso estaba expresando un sentimiento muy común en Europa entre los ilustrados del siglo XVIII. Muchos autores españoles y europeos de entonces tenían tal amplitud de visión, tan hondo sentido de los fundamentales valores humanos, y tal deseo de promover la cooperación internacional gracias a la mutua comprensión de los hombres de buena voluntad, que es lástima se perdiese con el surgimiento del espíritu nacionalista en el siglo pasado. "A todo hombre viviente... le miro como hermano", decía Cadalso en su poema "Sobre no querer escribir sátiras". Podían, por lo tanto, compartir las ideas de los extranjeros, y compartir a veces las formas literarias en que esas ideas se expresaban en el extranjero, sin sentirse faltos de inspiración u originalidad, ni, en algún sentido, traidores a su patria. 